\title{
KORELASI FENOTYPE DAN HASIL JAGUNG MANIS (Zea mays saccharata, Sturt) DI KECAMATAN RUMBAI PEKANBARU
}

\author{
SURTINAH ${ }^{1^{*}}$ \\ ${ }^{1}$ Program Studi Agroteknologi, Fakultas Pertanian \\ Universitas Lancang Kuning, Jl. Yos Sudarso Km. 8 Rumbai Pekanbaru \\ 1*e-mail: surtinah@unilak.ac.id
}

\begin{abstract}
ABSTRAK
Tujuan penelitian adalah untuk mengetahui hubungan antara pertumbuhan vegetative dengan hasil jagung manis yang ditanam di Kebun Percobaan Fakultas Pertanian Unilak. Rancangan lingkungan yang digunakan adalah rancangan acak lengkap dengan 20 ulangan. Analisis data menggunakan analis is korelasi. Parameter yang diamati adalah tinggi tanaman, jumlah daun, panjang daun, lebar daun, berat tongkol berkelobot, berat tongkol tanpa kelobot, panjang tongkol berkelobot, panjang tongkol tanpa kelobot. Hasil penelitian yang diperoleh bahwa tinggi tanaman, jumlah daun, dan lebar daun berkorelasi nyata terhadap berat tongkol tanpa kelobot, dan berkorelasi sangat nyata terhadap panjang tongkol berkelobot dan panjang tongkol tanpa kelobot. Tinggi tanaman, jumlah daun, dan lebar daun tidak memberikan korelasi yang nyata terhadap berat tongkol berkelobot. Berat tongkol berkelobot dengan berat tongkol tanpa kelobot berkorelasi nyata, dan panjang tongkol tanpa kelobot dengan berat tanpa kelobot menunjukkan korelasi nyata.
\end{abstract}

Kata Kunci: Jagung Manis, korelasi,vegetatif.

\begin{abstract}
The purpose of this research is to know the relationship between vegetative growth with sweet corn produced in experimental garden of Faculty of Agriculture Unilak. The environmental design used was a complete randomized design with 20 replications. Data analysis using correlation analysis. The parameters observed were plant height, leaf number, leaf length, leaf width, weight of cob weighing, cob weight without cornhusk, length of cob weighing, length of cob without cornhusk. The results showed that plant height, leaf number, and leaf width were significantly correlated with unbalanced cob weight, and correlated significantly with the length of cobs weighing and length of cobs without cornhusk. Plant height, leaf number, and leaf width did not give a significant correlation to the weight of cobs weighing. Weight of cobs weighing with unobstructed weight of cobs without real correlated weight, and long cobs without weight with weightlessness showed no real correlation.
\end{abstract}

Keywords: Sweet corn,corelation, vegetative.

Diterima: 15 April 2018, disetujui 15 Juli 2018

\section{PENDAHULUAN}

Prospek perkembangan budidaya Hal ini berhubungan dengan pertambahan jagung manis di Pekanbaru sangat pesat. jumlah penduduk yang bertambah setiap 
tahun. Pertambahan jumlah penduduk selalu diikuti dengan bertambahnya kebutuhan akan pangan. Jagung manis merupakan salah satu bahan pangan yang dapat menggantikan bahan pangan pokok. Rasanya yang manis dan seratnya yang lunak menjadi dasar komoditi ini diminati oleh masyarakat. Kondisi ini yang menyebabkan jagung manis dijadikan salah satu komoditi unggulan untuk dikembangkan.

Produksi jagung manis di Pekanbaru baru mencapai 28.052 ton hektar ${ }^{-1}$ dengan luas panen 11.748 hektar (BPS, 2014). Distan (2012) melaporkan bahwa produksi jagung manis di Riau sangat perlu untuk dikembangkan, karena Riau masih kekurangan pasokan sebesar 12191.67 ton, sehingga untuk menutupi kekurangan ini Riau terus memasok jagung manis dari Sumatera Barat. Surtinah (2017) melaporkan bahwa di Riau produksi jagung manis hanya 2.39 ton hektar ${ }^{-1}$, sedangkan produksi jagung manis mencapai 10.6 ton hektar ${ }^{-1}$. Produksi yang rendah ini disebabkan karena lingkungan tempat tumbuhnya kurang mendukung. Salah satu penyebabnya adalah kurangnya bahan organik dalam tanah PMK di lokasi penelitian (Surtinah, 2013). Kondisi tanah yang kurang subur merupakan faktor penghambat dalam produksi tanaman, tetapi kondisi ini dapat diselesaikan dengan penambahan bahan organik (Lidar, dan Surtinah, 2012)

\section{METODE PENELITIAN}

\section{Tempat dan Waktu}

Penelitian dilaksanakan di Kebun Percobaan Fakultas Pertanian Universitas Lancang Kuning dengan ketinggian tempat $20 \mathrm{~m}$ dari permukaan laut. Penelitian dilakukan pada bulan Februari sampai dengan April 2018. Jenis tanah Podsolik Merah Kuning (PMK).
Surtinah dan Nurwati (2018) melaporkan bahwa varietas Bonanza merupakan salah satu varietas yang dapat dikembangkan di Pekanbaru. Dan pada penelitian yang lain (Surtinah, 2015) melaporkan bahwa Varietas Bonanza menghasilkan berat tongkol tanpa kelobot 295 g bila dipanen pada pukul 17.00 dan pada umur panen 65 hari. Penelitian yang berbeda dilaporkan oleh Syafruddin, Nurhayati, dan Ratna (2012) dengan menggunakan varietas yang sama dan pemberian pupuk NPK cair memperlihatkan pertumbuhan dan hasil yang tinggi. Varietas Bonanza yang dibudidayakan bersama dengan kacang tanah menghasilkan berat tongkol 319.45 gram (Irvendi, 2016).

Varietas Bonanza yang ditumpangsarikan dengan kangkung sutera menghasilkan berat tongkol tanpa kelobot 397.50 gram (Surtinah, Susi, dan Lestari, 2016). Ebtan, Sugiharto, dan Widaryanto (2014) melaporkan bahwa berat tongkol berkelobot varietas Bonanza mencapai 421 gram dengan keberadaan gulma teki di sekitar tanaman. Surtinah dan Nurwati (2018) melaporkan bahwa varietas Bonanza menghasilkan berat tongkol berkelobot sebesar 466.67 gram pada penelitian yang menggunakan delapan varietas sebagai perlakuan. Ningsih, Marlina, dan Hawayanti (2015) melaporkan bahwa produksi yang tertinggi dicapai oleh varietas Bonanza yaitu $4.23 \mathrm{~kg}$ petak $^{-}$, setara dengan 11.280 ton $\mathrm{ha}^{-1}$

\section{Metode Penelitian}

Penelitian dilaksanakan secara eksperimen dengan menggunakan rancangan lingkungan acak lengkap dengan 20 kali ulangan, Data dianalisis menggunakan analisis korelasi antara pertumbuhan tanaman dengan produksi jagung manis. 


\section{Persiapan lahan}

Tanah diolah dua kali agar pertumbuhan dan perkembangan akar jagung menjadi lebih bagus, yang akan berdampak terhadap pertumbuhan dan perkembangan tanaman jagung manis.

\section{Pembuatan plot}

Plot yang digunakan berjumlah 20 plot dengan ukuran $150 \times 100 \mathrm{~cm}$, setiap plot berisi 10 tanaman dan tiga tanaman dijadikan tanaman sampel.

\section{Penanaman}

Benih

ditanam dengan menggunakan tugal dengan jarak tanam $20 \times 75 \mathrm{~cm}$, setiap lubang diisi dua benih, dan setelah berkecambah dibiarkan satu tanaman untuk tiap lubang tanam.

\section{Pemeliharaan}

Pemupukan tanaman jagung diberikan sebanyak tiga kali, dengan dosis 3 gram untuk pemberian pertama, yang diberikan pada saat tanam, 5 gram diberikan pada minggu ke 3 setelah tanam, dan 5 grram diberikan pada minggu ke 5 setelah tanam, seluruh pupuk diberikan dengan cara ditugal di sebelah dalah barisan tanaman.

\section{HASIL DAN PEMBAHASAN}

Hasil analisis data untuk seluruh variable yang dianalisis ditampilkan pada Tabel 1. Pada tabel tersebut sekaligus Tinggi tanaman jagung berpengaruh nyata terhadap berat tongkol tanpa kelobot, berpengaruh sangat nyata terhadap panjang tongkol tanpa kelobot, dan panjang tongkol berkelobot. Tinggi tanaman memberikan pengaruh terhadap hasil, diduga disebabkna oleh intensitas cahaya yang diperoleh tanaman akan semakin banyak bila tanaman semakin tinggi. Tanaman jagung merupakan tanaman yang membutuhkan cahaya yang banyak untuk tumbuh dan berkembang. Dan cahaya yang diproleh tanaman akan menjadi bahan dasar untuk pembentukan nutrisi yang dibutuhkan tanaman.
40 ton hektar ${ }^{-1}\left(6 \mathrm{~kg} \mathrm{plot}^{-1}\right)$ pupuk kandang diberikan secara merata untuk setiap plot, dan diberikan pada saat pengolahan tanah kedua. Pada minggu ke tiga tanaman disemprot dengan menggunakan Decis dengan konsentrasi 2 cc liter $^{-1}$ air, dan pada minggu keempat setalah tanam diberikan Dithane M-45 dengan konsentrasi $2 \mathrm{~g}$ liter $^{-1}$ air, dan diulangi pemberiannya pada minggu kedelapan setelah tanam. Penyiraman dilakukan dua kali sehari sebanyal 1 liter tanaman ${ }^{-1}$.

Buah dijarangkan pada umur 52 hari setelah tanam dan buah yang dibiarkan adalah buah yang berada paling atas. Gulma disiang pada umur dua minggu setelah tanam, beramaan dengan pembumbunan pertama. Penyiangan gulma dilakukan seminggu sekali.

Parameter pengamatan dilakukan terhadap tinggi tanaman, jumlah daun, panjang daun, lebar daun, berat tongkol berkelobot, berat tongkol tanpa kelobot, panjang tongkol berkelobot, dan panjang tongkol tanpa kelobot.

dapat dilihat hasil keeratan hubungan antara variable yang diuji.

Surtinah et al., 2016) melaporkan bahwa berat tongkol berkelobot varietas Bonanza 397.50 gram, berat tongkol tanpa kelobot 248.67 gram dengan pemberian pupuk yang sama dengan penelitian ini. Pada penelitian jagung manis yang ditanam secara tunggal diperoleh berat tongkol berkelobot 495.00 gram, dan berat tongkol tanpa kelobot 330.00 gram (Surtinah, Susi, dan Lestari, 2016b). Pada penelitian dengan perlakuan pemberian pupuk Bio extrim dan zpt Hormax dihasilkan berat tongkol berkelobot 434.51 gram, dan berat 
tongkol tanpa kelobot 316.04 gram (Surtinah, 2017).

Korelasi jumlah daun dengan berat tanpa kelobot, panjang tanpa kelobot, dan panjang berkelobot berpengaruh nyata dan sangat nyata. Sedangkan panjang daun tidak memberikan pengaruh nyata terhadap komponen hasil jagung manis. Lebar daun memberikan pengaruh nyata dan sangat nyata terhadap berat tanpa kelobot, panjang tanpa kelobot dan panjang berkelobot. Daun sesuai fungsinya sebagai tempat terselenggaranya proses fotosintesis memiliki konstribusi terhadap hasil jagung manis. Daun yang aktif melakukan fotosintesis akan memberikan sumbangan yang besar terhadap akumulasi bahan kering yang akan dikirimkan ke sink sebagai hasil produksi.

Yulisma (2011) melaporkan bahwa tanaman jagung dengan luas daun terluas yaitu $5996 \mathrm{~cm}^{2}$ tanaman $^{-}$ ${ }^{1}$ menghasilkan bobot kering tanaman yang tertinggi yaitu 113.4 gram tanaman ${ }^{1}$. Bobot kering tanaman adalah gambaran dari bahan kering yang terbentuk akibat dari proses fotosintesis. Fotosintesis merupakan kegiatan fisiologis yang dilakukan oleh tanaman pada umumnya dilaksanakan pada organ daun. Pada penelitian yang sama diperoleh laju asimilasi bersih yang tertinggi juga pada tanaman dengan luas daun terluas, yang menghasilkan berat pipilan kering tertinggi yaitu $4627 \mathrm{~kg}$ hektar ${ }^{-1}$.

Surtinah et al. (2016a) melaporkan bahwa tanaman jagung manis dengan lebar daun $11.33 \mathrm{~cm}$ menghasilkan berat tongkol berkelobot 511.67 gram, berat tongkol tanpa kelobot 317.33 gram, dan panjang tongkol berkelobot $23.67 \mathrm{~cm}$, dan merupakan hasil terbaik untuk semua parameter pengamatan. Pada penelitian berikutnya Surtinah et al. (2016b) menemukan bahwa tanaman kangkung yang ditanam tanpa ditumpangsarikan menghasilkan bert tongkol berkelobot 495.00 gram, dan berat tongkol tanpa kelobot 330.00 gram. (Surtinah \& Lidar, 2017) melaporkan bahwa terdapat hubungan yang erat antara jumlah daun dengan kadar gula biji jagung manis. Diketahui bahwa kadar gula biji merupakan bentuk lain dari padatan terlarut dalam biji jagung manis. Kadar gula merupakan hasil fotosintesis yang akan berubah menjadi sukrosa dan fruktosa melalui proses metabolisme, dan fotosintesis erat kaitannya denganorgan tanaman daun.

Pada penelitian yang lain ditemukan bahwa tanaman jagung manis dengan jumlah daun yang tertinggi menghasilkan berat tongkol tertinggi pula, dan berat tongkol per petak yang tertinggi juga (Ningsih et al., 2015).

Korelasi antara panjang tongkol berkelobot sangat erat hubungan hubungannya dengan panjang tongkol tanpa kelobot, begitu juga panjang tongkol tanpa kelobot sangar erat hubungannya dengan berat tongkol tanpa kelobot, dan berat berkelobot dengan berat tanpa kelobot memiliki hubungan yang erat. Kelobot tanaman jagung manis merupakan modifkasi dari organ daun pada tanaman jagung manis, sehingga fungsinya juga sama yaitu dapat melakukan fotosintesis, karena kelobot jagung memiliki klorofil yang berperan sebagai penangkap cahaya untuk memecah molekul air pada reaksi terang dalam proses fotosintesis, dan fotosintat yang dihasilkan akan disimpan dalam organ penyimpan seperti tongkol untuk di alokasikan pada saat proses generatif yaitu pertumbuhan dan perkembangan biji (Surtinah, 2017) 
Tabel 1. Korelasi antara variable yang diamati pada saat panen jagung manis

\begin{tabular}{|c|c|c|c|c|c|c|c|c|}
\hline $\begin{array}{c}\text { Parameter } \\
\text { pengamatan }\end{array}$ & $\begin{array}{l}\text { Berat } \\
\text { tongkol } \\
\text { tanpa } \\
\text { kelobot } \\
(\mathrm{g})\end{array}$ & $\begin{array}{c}\text { Berat } \\
\text { tongkol } \\
\text { berkelobot } \\
\text { (g) }\end{array}$ & $\begin{array}{c}\text { Panjang } \\
\text { tongkol } \\
\text { tanpa } \\
\text { kelobot } \\
(\mathrm{Cm})\end{array}$ & $\begin{array}{c}\text { Panjang } \\
\text { tongkol } \\
\text { berkelobot } \\
(\mathrm{Cm})\end{array}$ & $\begin{array}{r}\text { Lebar } \\
\text { daun } \\
(\mathrm{Cm})\end{array}$ & $\begin{array}{c}\text { Panjang } \\
\text { daun } \\
(\mathrm{Cm})\end{array}$ & $\begin{array}{c}\text { Jumlah } \\
\text { daun } \\
\text { (Helai) }\end{array}$ & $\begin{array}{c}\text { Tinggi } \\
\text { tanaman } \\
(\mathrm{Cm})\end{array}$ \\
\hline \multicolumn{9}{|l|}{ Brt Tkl. } \\
\hline Tanpa & 1 & & & & & & & \\
\hline Klbt.(g) & & & & & & & & \\
\hline $\begin{array}{l}\text { Brt Tkl Bklbt } \\
\text { (g) }\end{array}$ & $.445^{*}$ & 1 & & & & & & \\
\hline $\begin{array}{l}\text { Pjg.Tkl Bklbt } \\
(\mathrm{Cm})\end{array}$ & $.565^{* *}$ & .313 & 1 & & & & & \\
\hline $\begin{array}{l}\text { Pjg.Tkl.Tanpa } \\
\text { Klbt (Cm) }\end{array}$ & .442 & .392 & $.971^{* *}$ & 1 & & & & \\
\hline $\begin{array}{l}\text { Lbr.Daun } \\
(\mathrm{Cm})\end{array}$ & $.517^{*}$ & .400 & $.980^{* *}$ & $.986^{* *}$ & 1 & & & \\
\hline $\begin{array}{l}\text { Pjg. Daun } \\
(\mathrm{Cm})\end{array}$ & -.201 & .125 & -.249 & -.165 & -.188 & 1 & & \\
\hline $\begin{array}{l}\text { Jml.Daun } \\
\text { (helai) }\end{array}$ & $.526^{*}$ & .413 & $.965^{* *}$ & $.968^{* *}$ & $.976^{* *}$ & -.273 & 1 & \\
\hline $\begin{array}{l}\text { Tinggi Tan. } \\
(\mathrm{Cm})\end{array}$ & $.529^{*}$ & .366 & $.983^{* *}$ & $.980^{* *}$ & $.995^{* *}$ & -.196 & $.979^{* *}$ & 1 \\
\hline
\end{tabular}

**. Correlation is significant at the 0.01 level (2-tailed).

*. Correlation is significant at the 0.05 level (2-tailed).

\section{KESIMPULAN}

Hasil penelitian yang diperoleh bahwa tinggi tanaman, jumlah daun, dan lebar daun berkorelasi nyata terhadap berat tongkol tanpa kelobot, dan berkorelasi sangat nyata terhadap panjang tongkol berkelobot dan panjang tongkol tanpa kelobot. Tinggi tanaman, jumlah

\section{UCAPAN TERIMA KASIH}

Kepada pimpinan Unilak diucapkan terimakasih atas perhatian dan fasilitas yang berupa dana penelitian dan fasilitas penelitian yang digunakan.

\section{DAFTAR PUSTAKA}

BPS. (2014). Produksi Padi dan Palawija. Katalog Badan Pusat Statistik Provinsi Riau. Pekanbaru. daun, dan lebar daun tidak memberikan korelasi yang nyata terhadap berat tongkol berkelobot. Berat tongkol berkelobot dengan berat tongkol tanpa kelobot berkorelasi nyata, dan panjang tongkol tanpa kelobot dengan berat tanpa kelobot menunjukkan korelasi nyata.

Terimakasih juga kepad Ketua LPPM Unilak yang telah memfasilitasi kegiatan penelitian ini baik secara administratif maupun pelayanan yang lainnya.
Distan. (2012). Petunjuk Teknis Peningkatan Mutu Intensifikasi (PMI) dan Pengembangan Tanaman 
Jagung. Dinas Tanaman Pangan dan Hortikultura Provinsi Riau.

Irvendi. (2016). Pertumbuhan dan Hasil Varietas Jagung Manis (Zea mays saccharata Sturt) dalam Tumpangsari Kacang Tanah (Arachis hipogea L.). J. Agrotropika , 3(3), 1-10.

Lidar, S. Surtinah.(2012). Respon Tanaman Jagung Manis (Zea mays saccharata, Sturt) Akibat Pemberian Tiens Golden Harvest. Jurnal Ilmiah Pertanian, 8(2), 1-5.

Ningsih, N. D., Marlina, N., \& Hawayanti, E. (2015). Pengaruh Jenis Pupuk Organik terhadap Pertumbuhan dan Produksi Beberapa Varietas Jagung Manis (Zea mays saccharata Sturt). J. Klorofil, $X(2)$, 93-100.

Ringga Ebtan, S., Sugiharto, A. N., \& Widaryanto, E. (2014). Ketahanan Beberapa Varietas Jagung Manis (Zea mays Saccharata Sturt) terhadap Populasi Gulma Teki (Cyperus rotundus). J. Produksi Tanaman, 1(6), 471-477.

SURTINAH, S. (2013). PENGUJIAN KANDUNGAN UNSUR HARA DALAM KOMPOS YANG BERASAL DARI SERASAH TANAMAN JAGUNG MANIS (Zea mays saccharata). Jurnal Ilmiah Pertanian, 11(1), 11-17.

Surtinah, S. (2017). POTENSI HASIL JAGUNG MANIS (Zea mays saccharata, Sturt) DENGAN PEMBERIAN PAKET TEKNOLOGI PUPUK DAN ZAT PENGATUR TUMBUH. Jurnal BiBieT, 2(1), 37-44.
Surtinah, S. (2015). PENGUJIAN TIGA VARIETAS JAGUNG MANIS (Zea mays saccharata) DI RUMBAI KOTA PEKANBARU. Jurnal Ilmiah Pertanian, 12(1), 37-43.

Surtinah, S., Lidar, S., (2017). Pertumbuhan Vegetatif dan Kadar Gula Biji Jagung Manis (Zea mays saccharata, Sturt) di Pekanbaru. Jurnal Ilmiah Pertanian, 13(2).

Surtinah, S., Nurwati, N. (2018, May). Selecting the Right Varieties in Riau Main Island: Sweet Corn Context. In IOP Conference Series: Earth and Environmental Science (Vol. 156, No. 1, p. 012062). IOP Publishing.

Surtinah, S., Susi, N., \& Lestari, S. U. (2016). Komparasi Tampilan dan Hasil Lima Varietas Jagung Manis (Zea mays saccharata, Sturt) di Kota Pekanbaru. Jurnal Ilmiah Pertanian, 13(1).

Surtinah, S., Susi, N., \& Lestari, S. U. (2016). Optimasi Lahan dengan Sistem Tumpangsari Jagung Manis (Zea mays saccharata, Strurt) dan Kangkung Sutera (Ipomea reptans) di Pekanbaru. Jurnal Ilmiah Pertanian, 12(2).

Syafruddin, Nurhayati, \& R, W. (2012). Pengaruh jenis pupuk terhadap pertumbuhan dan hasil beberapa varietas jagung manis. J. Floratek, $7(1)$.

Yulisma. (2011). Pertumbuhan dn Hasil Beberapa Varietas Jagung pada Berbagai Jarak Tanam. J. Penelitian Pertanian Tanaman Pangan, 30(3). 